\title{
Ares Launch Vehicles Lean Practices Case Study
}

\author{
Rajiv Doreswamy, Project Integration Manager \\ Timothy A. Self, Chief of Staff \\ Ares Projects Office \\ Marshall Space Flight Center \\ Huntsville, AL 35812 \\ 256-544-7903 \\ rajiv.doreswamy@nasa.gov
}

Abstract-The Ares launch vehicles team, managed by the Ares Projects Office (APO) at NASA Marshall Space Flight Center, has completed the Ares I Crew Launch Vehicle System Requirements Review and System Definition Review and early design work for the Ares V Cargo Launch Vehicle. This paper provides examples of how Lean Manufacturing, Kaizen events, and Six Sigma practices are helping APO deliver a new space transportation capability on time and within budget, while still meeting stringent technical requirements. For example, Lean philosophies have been applied to numerous process definition efforts and existing process improvement activities, including the Ares I-X test flight Certificate of Flight Readiness (CoFR) process, risk management process, and review board organization and processes. Ares executives learned Lean practices firsthand, making the team "smart buyers" during proposal reviews and instilling the team with a sense of what is meant by "value-added" activities. Since the goal of the APO is to field launch vehicles at a reasonable cost and on an ambitious schedule, adopting Lean philosophies and practices will be crucial to the Ares Project's long-term success. $^{12}$

\section{TABLE OF CONTENTS}

1. ARES Project INTRODUCTION 1

2. LEAN EVENTS IN ARES I-X

3. Lean, Six Sigma, AND Kaizen Practices in the ARES PROJECTS OFFICE.............................................4

CONCLUSION...................................................................6

REFERENCES ................................................................7

BIOGRAPHIES.

\section{ARES Project InTRoduction}

\section{Vehicle Background and Mission Scenario}

The National Aeronautics and Space Administration (NASA) is designing and building the next generation of vehicles to enable human exploration of the Moon, Mars, and other destinations in the solar system. These vehicles are key components of the nation's strategic future in space.

The Exploration Systems Architecture Study (ESAS), completed in 2005, established the high-level requirements (including design reference missions) for the launch vehicles and spacecraft necessary to fulfill the requirements for NASA's exploration mission [1]. Since that study concluded, the team has performed extensive vehicle analyses that refined original recommendations made by the ESAS and that resulted in hardware commonality decisions to reduce technical, schedule, and budget risk.

Following the Global Exploration Strategy, a long-term space exploration strategy developed by 14 of the world's space agencies in 2006, and based on the 2005 ESAS recommendations, NASA plans to retire the Space Shuttle in 2010. Ares I and Ares V will replace the Shuttle for missions to the International Space Station (ISS) as well as provide safe, reliable, and cost-effective space transportation systems for crew and cargo travel to the Moon, Mars, and beyond. The Ares I (Figure 1) that lofts the Orion crew exploration vehicle into orbit early next decade is an in-line configuration with a Space Shuttle legacy 5-segment Reusable Solid Rocket Booster (RSRB) as the first stage. On top of the first stage, a new upper stage provides fuel to a J-2X engine, an evolution from the J-2 engine used to power the upper stages of the Apollo Program's Saturn IB and Saturn V. The heavy-lift Ares V, seen in Figure 2, will carry the lunar lander to orbit to rendezvous with Orion and initiate the Trans-Lunar Injection (TLI) burn to send the Orion and lunar lander on to the Moon. Ares V also builds on legacy hardware, including two RSRBs and a Saturn-class core propulsion stage with five clustered expendable RS -68 engines. Late next decade, the Ares V Earth departure stage will also be powered by the $\mathrm{J}-2 \mathrm{X}$ engine. After arriving in lunar orbit, the crew will transfer to the lunar lander, which will transport them to and from the Moon's surface while the Orion vehicle waits in orbit. After completing their mission, the astronauts will return to the crew capsule for the return trip to Earth.

\footnotetext{
1 U.S. Government work not protected by U.S. copyright.

${ }^{2}$ IEEEAC paper \#1589, Version 4, Updated November 30, 2007
} 


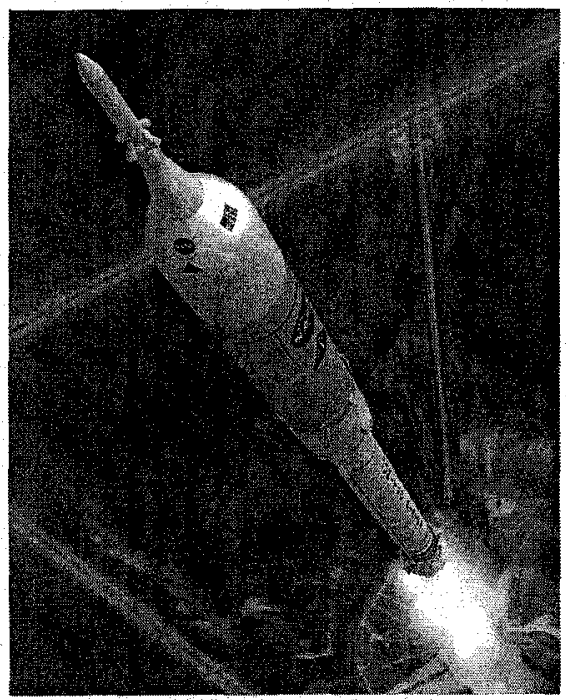

Figure 1 - Ares I Crew Launch Vehicle

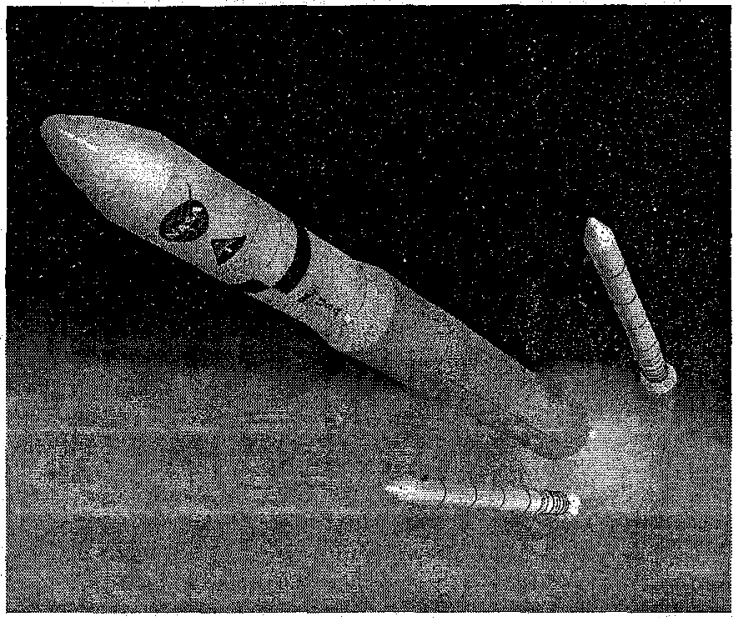

Figure 2 - Ares V Cargo Launch Vehicle

APO has analyzed its business practices extensively to meet the nation's strategic goal of returning humans to the Moon for scientific exploration and preparing to place astronauts on Mars. The desired goal is to dramatically reduce the cost of owning and operating the Agency's next-generation space fleet, as directed in the Constellation Program's Architecture Requirements Document [2].

\section{Background of Lean Practices in the Ares Projects Office}

This paper provides several examples of how Lean Manufacturing, Kaizen, and Six Sigma practices are helping to deliver a new space transportation capability on time and within budget, while still meeting the technical requirements of human-rated spaceflight. Lean and Six Sigma practices are defined by the Constellation Program's Affordability Plan as a business improvement methodology that combines the best attributes of Lean Manufacturing - which focuses on the speed at which a product is delivered - and of Six Sigma, which focuses on delivering products that meet stringent quality standards.

\section{LeAN EVENTS IN ARES I-X}

\section{Ares I-X Flight Test Background}

Like the Apollo Program's Saturn launch vehicles, the Ares launch vehicles will undergo a series of development, verification, and orbital flight tests as well as static ground tests. These tests will be completed before the first humans are sent into orbit in Orion aboard Ares I as early as 2013, with regular missions to the ISS slated to begin no later than 2015. Ares V will begin testing in 2018, with the first lunar mission occurring in the 2020 time frame. The first Ares I flight test, known as the Ares I-X mission, is scheduled to occur in April 2009, and will test NASA's ability to control a vehicle with a similar size and shape, as the one depicted in Figure 3.

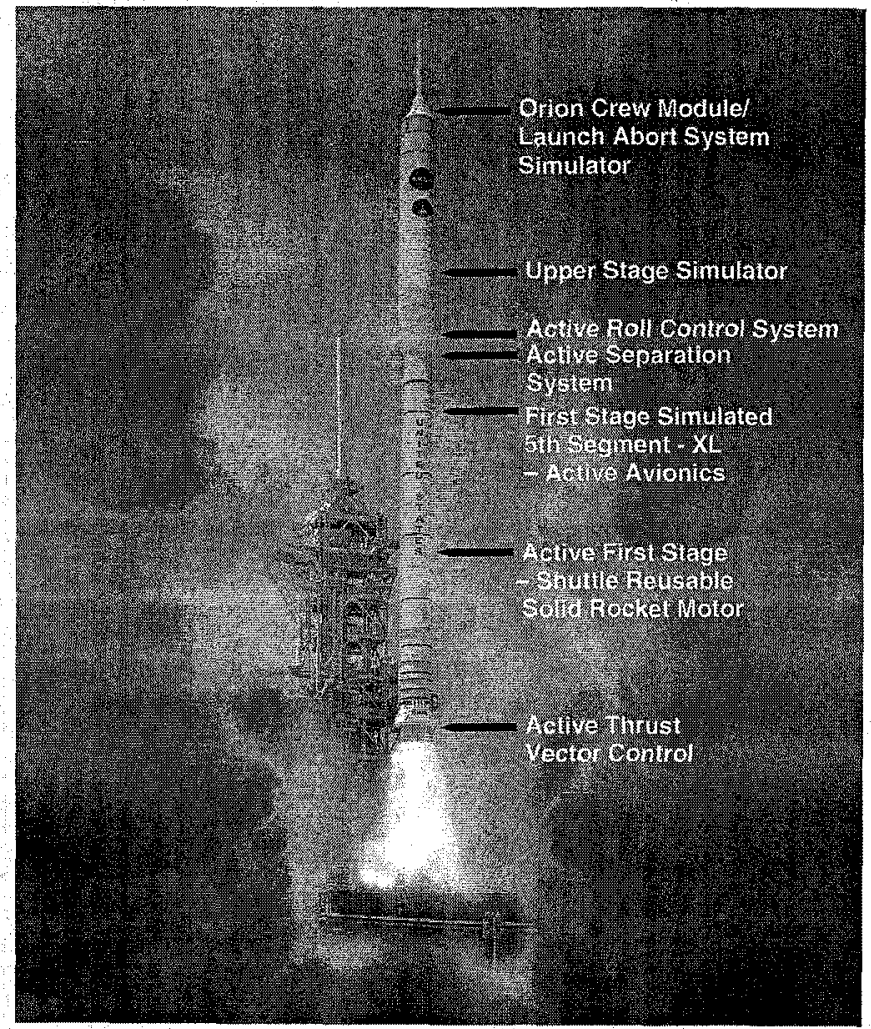

Figure 3-Ares I-X flight test vehicle elements

The Ares I-X flight test vehicle will incorporate a mix of flight-like and mass simulation hardware, reflecting a configuration similar in outer mold line, mass, and weight to the operational vehicle. It will be powered by a foursegment RSRB, which is currently in Shuttle inventory, and will be modified to include a fifth, inert segment that makes it approximately the same size and weight as the fivesegment RSRB, which will be available for the next flight test in 2012. The Ares I-X flight profile will closely approximate the flight conditions that the Ares I will experience through Mach 4.5 , at an altitude of about 130,000 feet, through maximum dynamic pressure ("Max Q"), which is around 800 pounds per square foot. To maintain a constant attitude throughout flight, the vehicle will include an active Roll Control System (RoCS), which 
also will measure and respond to the amount of roll torque generated during flight. The flight will aid the timing of first stage burnout, first stage separation, and upper stage ignition, which should occur around 130 seconds into flight.

\section{Lean Practices Applied to the Ares I-X Organization}

The Constellation Program was designed to return human beings to the Moon in preparation for the first human footprints on Mars - and to do so within NASA's existing budget. This program philosophy demands reduced costs to enable NASA to spend less money on human spaceflight operations and more on actual exploration activities. To meet this live-within-its-means objective, the Agency is instituting industry best practices, such as "Lean Manufacturing" in an effort to reduce costs and increase efficiency in the post-Shuttle era.

Lean processes emphasize reducing the overall cost of doing business and improving the value stream [3]. APO has been applying Lean thinking to many of its activities, including the Ares I-X flight test. The first step in this process is careful analysis and mapping of the value stream, as shown in Figure 4.

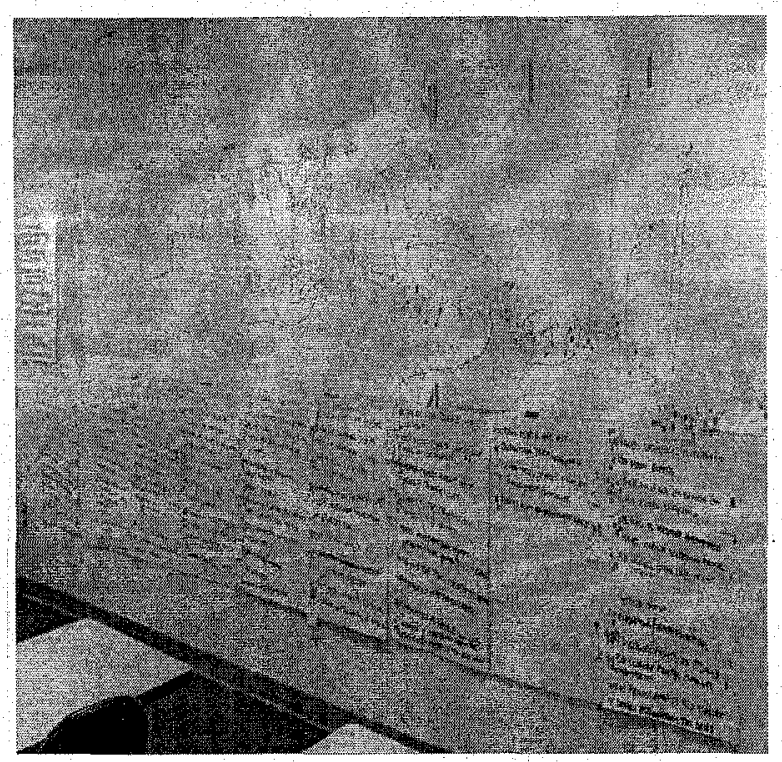

Figure 4. Value stream mapping for one of many processes within the Ares Projects Office

In late April and early May 2007, managers from across the Agency met at Langley Research Center (LaRC) in Hampton, Virginia, to discuss how to implement Lean processes for the Ares I-X test flight. The need for a Lean effort was identified, in part, because different levels of the Ares I-X organization had conflicting notions about what level of safety to apply to a one-time uncrewed test of a prototype Ares I vehicle. As a result of this meeting, the various elements performing Ares I-X activities were unified under one Mission Manager reporting to the
Constellation Program (CxP) Office, thereby reducing the amount of bureaucracy. Both the Flight Test Vehicle (FTV) and Ground Operations (GO) elements now report to one Mission Management Office (MMO). Further, to reduce decision-making and approval times, the Ares I-X Mission reduced its number of independent review boards from 10 to 4. These organizational changes were necessary to ensure that the Ares I-X team is able to react quickly to challenges and achieve the April 2009 launch date.

\section{Lean Practices Applied to the Ares I-X Schedule}

Following the decision to establish the Ares I-X MMO, the team held a series of meetings to apply Lean practices to their hardware development processes. The goal of this "leaner" effort was to incorporate 60 calendar days of additional margin into the overall flight test schedule-by managing to the earlier launch date rather than potentially face slips that would push the launch date past April 2009.

Each Lean event included senior members of the MMO and affected parties with authority to make decisions for the individual vehicle elements, including the First Stage (FS), Upper Stage Simulator (USS), Avionics, RoCS, Command Module/Launch Abort System (CM/LAS) simulator, Ground Systems (GS), Ground Operations, and Systems Engineering and Integration (SE\&I).

The general flow of each of these events included identifying:

O The current state

O The ideal state

O A realistic future/target state

O Assumptions, decisions, and/or actions to be taken to achieve the future state

O Meeting outputs

Each element area had its own particular activities which, under the Lean Manufacturing philosophy, could be described as value added. These included hardware manufacturing, delivery, assembly, and integration. To meet the 60-day goal, participants were required to clearly state which activities were required to deliver their particular work on time. Sometimes this meant reordering the sequence of hardware deliveries or tests; shifting work (such as integration or inspection) from production sites to the vehicle preparation site at Kennedy Space Center (KSC) in Florida; or reducing the number of times hardware was handled or inspected.

First Stage Lean Event Results-The first business improvement for the Ares I-X First Stage was to expedite the delivery of finished components to support an assembly schedule that would move the launch back 60 days. This need applied to all of the stage's new forward structures, including the inert fifth segment, forward skirt, forward skirt extension, Main Parachute Support System (MPSS), and frustum. 
The primary adjustments made to the First Stage hardware were to change the sequence of hardware delivery, to predrill some hardware to facilitate quicker assembly, and to defer avionics testing until the hardware reached KSC. These changes significantly reduced the amount of touchlabor time on the hardware from 4 to 30 days, depending on the hardware.

\section{Avionics Lean Event Results-}

The vehicle's avionics required adjustments to hardware and software development, testing, and inspection (verification). The primary methods of adjusting the schedule included establishing clear and hard deadlines for items which had been delayed, allowing work to go forward; condensing and reducing the number of check points; verifying work on-site at $\mathrm{KSC}$; and rescheduling the delivery of some hardware components.

Roll Control System Lean Event Results-The Roll Control System (RoCS) will use existing rocket engines harvested from Peacekeeper missiles, thus reducing the amount of new hardware to be built for this element. In addition, the RoCS schedule already had 30 days of margin. The RoCS team was able to find an additional 50 days of margin by agreeing to procure support hardware prior to the element's Critical Design Review (CDR) and by handing the hardware over to KSC's Hypergolic Maintenance Facility (HMF) for priority handling. The team also eliminated a fit check of the RoCS system into the vehicle. Instead, the team will use a qualification module to test the fit of the RoCS. Previously, the flight hardware was to have been put through the fit check before being moved to the HMF. Now, the RoCS will be delivered directly the HMF upon arrival at KSC.

Upper Stage Simulator (USS) and Command Module/Launch Abort System Simulator (CM/LAS)-Like the RoCS, the USS and CM/LAS schedules already had schedules that supported a 60-calendar-day pullback, so these groups did not need to make additional adjustments to their schedules.

Ground Systems/Ground Operations Lean Event Results Ground Systems (GS) comprises hardware devoted to servicing and supporting the Ares I-X flight test vehicle (FTV) prior to launch; Ground Operations (GO) are those activities associated with stacking and launching the FTV. With most of the up-front work going into the FTV, GS and GO were behind in development. Their biggest challenges were in procuring long-lead items and obtaining access to Launch Complex 39B to start modifying it for the Ares vehicle. Because the Ares vehicle is so much taller than the Space Shuttle 39B currently supports, several modifications will be needed, including a new lightning rod and launch pad stabilization to keep the FTV from swaying due to rollout or winds.

To resolve the long-lead issues, NASA streamlined its procurement process with United Space Alliance (USA), the prime contractor for GS/GO at $\mathrm{KSC}$, by reducing the legal review time from 42 to 28 days, enabling USA to go to work earlier. KSC's subcontracting procurement process was also reduced from 77 to 63 days. The most important change, however, was made to stacking operations. GO will modify existing cranes and support equipment within the Vehicle Assembly Building (VAB), to perform multiple operations simultaneously instead of handling one stack at a time. In addition, by increasing the number of work shifts, and by installing some avionics hardware prior to delivery, some activities can be completed more quickly. These modifications reduced vehicle stacking time from 1,400 to 1,201 hours.

A reordering of activities on the launch pad reduced pad flow from 7.5 days to 5.5 days. For example, the Ground Operations team reduced the number of activities that required the launch pad area to be cleared of personnel. They also reduced the number of times the Rotating Service Structure (RSS) had to be moved, eliminated servicing of the Hydraulic Power Unit (HPU), and combined the Integrated System Test (IST) with the Terminal Countdown Demonstration Test (TCDT).

Systems Engineering \& Integration Lean Event ResultsThe SE\&I group at LaRC was facing delays due to inefficient approval processes for Structures Integrated Design and Analysis (IDA), Development Flight Instrumentation (DFI), and Assembly Integration and Test (AIT). The Lean event for this group focused on streamlining (reducing the number of) review cycles for IDA and DFI. In the case of AIT, there was a lack of integration between the various vehicle element teams, which required clearer definition of roles and responsibilities within and among the element teams.

When all of these events were completed, each of the elements was able to restructure its processes to meet a 60 day schedule shift acceleration. The next steps will be to implement the changes recommended in the Lean events and re-baseline the schedule to match the new plans. It will also be important for the Ares I-X management team to communicate the assumptions made in the Lean event meetings and to execute any agreements or scope and budget changes based upon them.

\section{Lean, Six Sigma, AND KaIzen Practices in}

\section{THE ARES PROJECTS OFFICE}

Understanding that an organization must adapt to internal and external challenges, the Ares executive team has taken measurable steps to improve process and product efficiency by maximizing quality and reducing resource requirements. In the spring of 2007 , the Ares executives visited The Boeing Company's 787 production facilities in Renton, Washington, to learn firsthand how Boeing regained its market share from Airbus in part through Lean practices. 
This was an important lesson because Boeing managed to increase its market share through more aggressive pricing, requiring the company to develop new cost-saving manufacturing methods [4].

Among the efforts Boeing has made are to rely more heavily on its second-and third-tier suppliers to develop, supply, and deliver high-quality products on a "just-in-time" basis, rather than perform most of the work in-house at a central location [5]. This approach allows Boeing to focus more of its attention on the integration of large components and systems and total life cycle support. This type of supply chain would reduce the total life cycle cost of the Ares launch vehicles.

The visit with Boeing inspired the Ares leadership team to become champions through formal Lean training. The training has had at least two immediate impacts: (1) it made the team members "smart buyers" during the rocket hardware proposal review process; and (2) it instilled a better sense of what is meant by "value-added" activities. This mindset will enable APO to live within an austere budget, made even tighter by the continuing resolution imposed on the Agency's Fiscal Year 2007 operating plan.

Previously, Lean processes have applied only to production and operations activities. In-house instructors at Marshall Space Flight Center (MSFC), as shown in Figure 5, provided senior members of APO with 3 days of Lean training to find ways of identifying and concentrating on the value-added activities in the Ares launch vehicles' design and development processes. The Lean training gave leaders the tools they needed to identify value-added activities in their individual parts of the project and allowed them to create their own solutions.

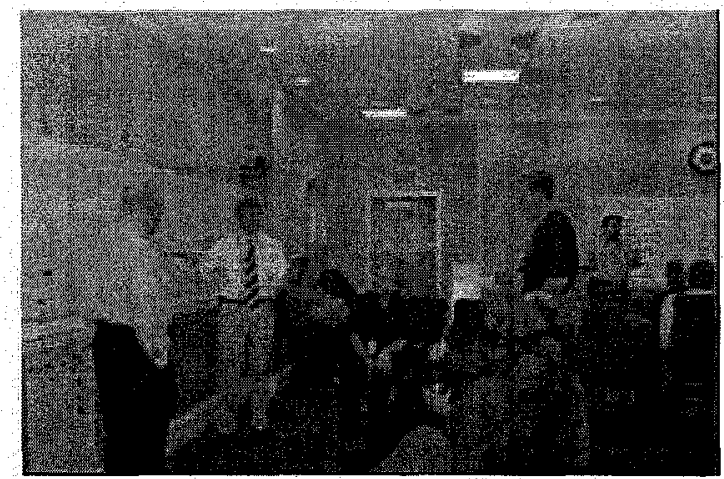

Figure 5 - Ares leaders undergo "Lean Six Sigma Champions" training at MSFC

One example of using Lean practices to improve Ares design and development related to the design teams' relationship with the S\&MA organization. There was some inefficiency present related to when S\&MA personnel were brought into the design loop. This resulted in S\&MA identifying problems later than desired, only to result in slipped schedules as the design teams strove to mitigate S\&MA findings [6]. The Lean process identified the critical need to include S\&MA earlier in the process to avoid such circumstances. As a result of this change, the S\&MA team is helping designers identify potential problems with safety, availability, reliability, and maintainability before the vehicle design is established.

Beyond the S\&MA process, the Ares I Upper Stage team is using Lean processes extensively for many of its activities, including manufacturing and assembly flow at the Michoud Assembly Facility (MAF), design reviews, approval flows, task descriptions, and configuration management.

Meanwhile, the overall Ares team has used Lean events to identify and improve communications both between vehicle elements (First Stage, Upper Stage, Launch Abort System, etc.) and among the various engineering disciplines (avionics, propulsion, thermal, etc.). Lean events related to communication processes resulted in a reorganization of Marshall Space Flight Center's Engineering Directorate so that it could support Ares better.

More Ares personnel have been trained on Lean processes, including lower-level managers, Contracting 'Officers' Technical Representatives (COTRs), and procurement personnel. By broadening this training throughout the project, APO has become a "smart buyer" of products and services. The more focused team members are on valueadded activities, the better stewards they become of taxpayer resources.

Lean thinking has not been the only best practice APO is using to provide value to NASA. Kaizen, the Japanese process of continuous improvement [7], has been used to analyze and improve tactical business processes within the value stream that can be addressed immediately.

Specific Kaizen efforts within Ares have been used to:

- Improve the workforce planning process

- Reduce the length of project integration meetings

- Improve APO's risk management process

- Improve requirements change, trade study, and design review processes [6].

Kaizen also has been used to develop new processes where none existed before. The Ares team has conducted 25 "Product Development" Kaizen events to meet a variety of needs, including manufacturing, safety, and cleaning processes. The specific outcomes have included:

- Optimizing the ground support equipment flow for handling the Ares I Upper Stage

- Merging the manufacturing flows at the Michoud Assembly Facility

- Resolving differences in welding and manufacturing processes between NASA and the Upper Stage prime contractor (Boeing).

- Optimizing the cleaning and corrosion protection processes

- Automating task description sheets

- Reviewing and updating process flows at KSC, 
including assembly, checkout, and launch activities

- Mapping and analyzing all manufacturing, assembly, and integration activities for the Ares V cargo launch vehicle.

Another best practice Ares uses is Six Sigma, which focuses on delivering products that meet stringent standards. Six Sigma is a quality improvement process, designed to reduce incidences of defects in manufacturing processes [8]. Given its emphasis on part and material quality, Six Sigma has its greatest influence on the manufacturing and assembly groups.

One recent example of implementing Six Sigma into Ares production has been in developing the friction stir welding tool for the Ares I Upper Stage, as seen in Figure 6. Friction stir welding uses the high rotational speed of a tool and the resulting frictional heat created from contact to crush, "stir" together, and forge a bond between two metal alloys. The technique is more reliable and maintains better material properties than conventional welding methods [9].

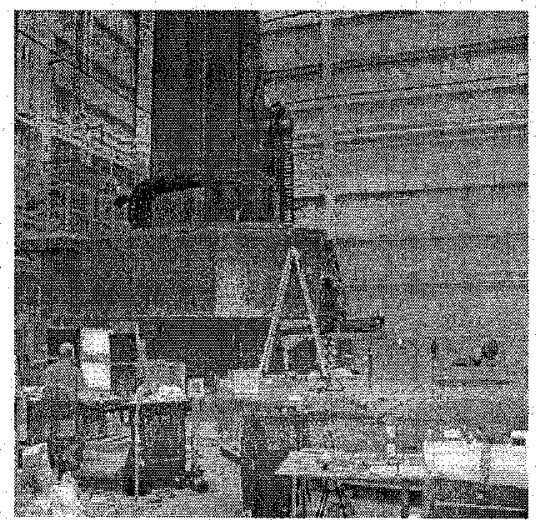

Figure 6. Friction Stir Welding tools will be used at the Michoud Assembly Facility and Marshall Space Flight Center's Building 4755.

These welds are applied between segments of the Upper Stage fuel and oxidizer tanks as well as between segments of the tank dome assemblies, as shown in Figure 7.

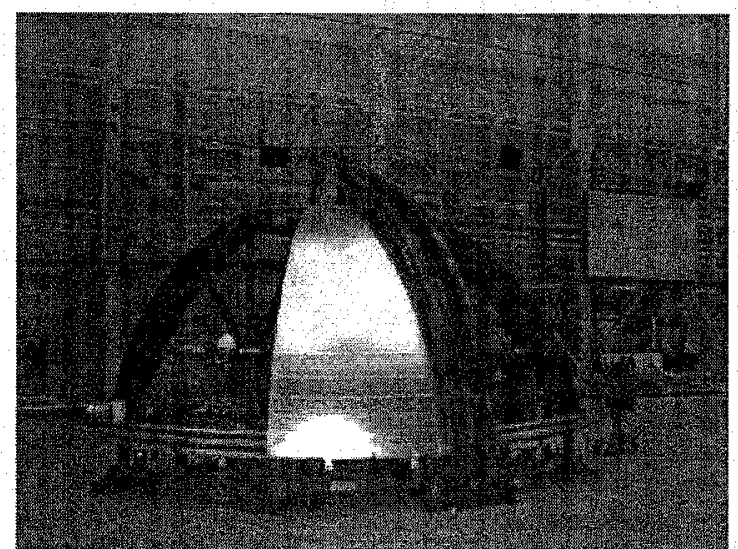

Figure 7. Tank dome assemblies like the one pictured above will be assembled using friction stir welding.
However, at the end of the weld, the single-piece pin tool is retracted and leaves a "keyhole." As a NASA press release explains,

To overcome these drawbacks, a Marshall Center welding engineer helped design an automatic retractable pin tool that uses a computer-controlled motor to automatically retract the pin into the shoulder of the tool at the end of the weld - preventing keyholes. This design allows the pin angle and length to be adjusted for changes in material thickness and results in a smooth hole closure at the end of the weld. [9]

The primary challenge with the weld plugs for these keyholes is preventing weaknesses in the tank. The manufacturing and assembly team applied Six Sigma processes to design an experiment to find the optimum machine settings for ensuring a nominal weld. As many as nine different variables can affect the quality of a keyhole weld, including the size of the hole, the angles of the backing plates, the spindle speed, and forging load. The analysis developed a set of values for determining the proper settings for welds, as well as determining the effectiveness of a weld if the settings were known but offnominal. The result was an unprecedented level of accuracy and minimization of weld stress (less than 1 kilo-pounds per square inch) [6]. Process improvements such as these can be applied throughout the Ares manufacturing process, as well as to other applications in the private sector.

The manufacturing and assembly team has used Six Sigma while designing the manufacturing process for Ares I in order to reduce errors up front, before the vehicle goes into regular production by Boeing. By designing for success in advance, NASA can eliminate production problems before they happen and reduce the number of problems that occur during the production phase. Once in a production mode, the prime contractors-including Boeing, Lockheed-Martin, and United Launch Alliance-will continue to use Six Sigma, Lean, and Kaizen activities to continuously improve the production of the Ares launch vehicles.

\section{Conclusion}

Given the forces affecting NASA's business and political climates, adopting Lean philosophies and practices is crucial to sustaining the Ares Project's long-term survival across decades. These progressive business practices are proving to be a source of insurance for the project by reducing risk and increasing the probability of mission success. They minimize waste and maximize value to NASA's customers and stakeholders. Lean thinking is key to accomplishing this complex, ambitious, and historic national exploration endeavor. 


\section{REFERENCES}

[1] National Aeronautics and Space Administration. Exploration Systems Architecture Study, Final Report, November 2005.

[2] National Aeronautics and Space Administration. Constellation Architecture Requirements Document, July 7,2006.

[3] Womack, James P. and Daniel T. Jones. Lean Thinking: Banish Waste and Create Wealth in Your Corporation. New York: Simon \& Schuster, 1996.

[4] O'neal, Mark. "New Plane Lifts Boeing in Contest for Top Seller.’ Chicago Tribune. May 27, 2005.

[5] Arkell, Debby. "The Evolution of Creation." Boeing Frontiers. March 2005.

[6] Mark Adrian and Patricia Fundum (NASA Lean Process Instructors, Adrian Technologies). Personal Interviews, September 26 and November 28, 2007.

[7] "Kaizen." iSixSigma.com. http://www.isixsigma.com/dictionary/Kaizen-42.htm.

[8] "Six Sigma - What is Six Sigma?"' iSixSigma.com. http://www.isixsigma.com/sixsigma/six sigma.asp.

[9] "NASA Marshall's Friction Stir Welding Technology Successfully Commercialized by Two Companies." NASA.gov.

http://www.msfc.nasa.gov/news/news/releases/2002/02009.html.

\section{BIOGRAPHIES}

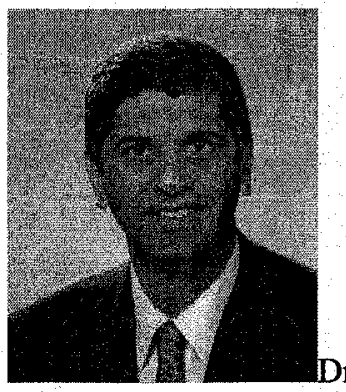

Dr. Rajiv Doreswamy is the Project Integration Manager of the Ares Projects Office at the Marshall Center. He also serves as the chief operating officer for the Ares Projects Office -- ensuring resources are in place to successfully execute this multi-billion dollar launch vehicle development project.

Before assuming this position in July 2007, Dr. Doreswamy spent more than 5 years at NASA Headquarters in Washington. Most recently, he served on the executive staff of the Associate Administrator. Prior experience includes more than 2 years of leadership positions within NASA's Exploration Systems Mission Directorate and nearly 2 years as Space Transportation Manager for the Office of Aerospace Technology.

Before transitioning to NASA Headquarters, Dr. Doreswamy spent more than 13 years at the MSFC, most recently as a resident manager for the ISS. He has earned three degrees in electrical engineering - a bachelor's in 1986 from the University of Florida in Gainesville; a master's in 1988 from Auburn University in Auburn, Alabama.; and a doctorate in 1999 from the University of Alabama in Tuscaloosa.

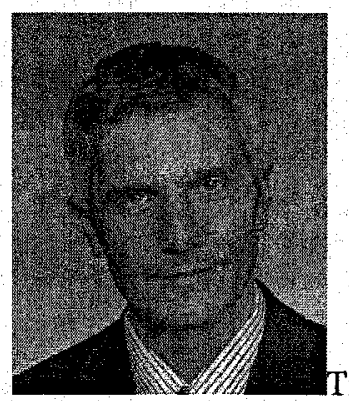

Timothy A. Self is the Chief of Staff for NASA MSFC's Ares Projects Office integration effort, where he is tasked with ensuring the Project Element Offices' effective contributions to project integration, planning, scheduling and configuration and data management. $\mathrm{He}$ has ten years of experience in NASA project management, program integration, and risk management.

In his current role, he is responsible for maintaining high level of communication among Project and Element Offices through staff and other forums, and ensures the Project's compliance with Center, Program, and Agency management policies and procedures. He has served in similar capacities for the Advanced Space Transportation Program, Next Generation Launch Technology Program and Space Transportation Programs and Projects Office.

Mr. Self is Vice-President of Self \& Associates, Inc. 